\title{
Bayer Classification of Visual Acuity Changes
}

National Cancer Institute

\section{Source}

National Cancer Institute. Bayer Classification of Visual Acuity Changes. NCI Thesaurus. Code C128445.

A grading system for best corrected visual acuity following treatment with anetumab ravtansine (BAY 94-9343). 